\title{
RNA-Binding Proteins: A Lesson in Repression
}

\author{
David G. Wells \\ Department of Molecular, Cellular, and Developmental Biology, Yale University, New Haven, Connecticut 06520
}

Regulation of protein expression in neurons by controlling not only when, but where, mRNAs are translated is likely to play an important role in neuronal function. In this review I focus on the mRNA-binding proteins that control mRNA translation in neurons and how they may participate in local, synaptodendritic protein synthesis.

Key words: synaptic plasticity; FMRP; mRNA translation; CPEB; ZBP; translation initiation

That protein synthesis may occur outside the neuronal cell body was first suggested in the early 1980s by the finding that polyribosomes are localized to subsynaptic regions (Steward and Levy, 1982). Of the potential functional significance for local protein synthesis, Steward and Levy (1982) wrote, "It is difficult to conceive of a situation which is intuitively more appealing as a mechanism for protein synthesis-dependent maintenance or modification of a synapse as a function of the activity over that synapse...." Indeed their excitement was shared by many researchers who, over the next decade, characterized the dendritic presence of the molecular machinery required for protein synthesis. More recently, a great deal of research has focused on the regulation of dendritic mRNA translation in neurons. Many studies have addressed two distinct questions: first, how are mRNAs transported into dendrites; and second, how is translation of these mRNAs regulated? It is now clear that both processes involve mRNA-binding proteins that are primarily bound to the 3 '-untranslated region (UTR) of responsive mRNAs. Although several mRNA-binding proteins that regulate $\mathrm{mRNA}$ transport and translation in neurons have been described, identification of the target mRNAs to which they bind has lagged behind. This review focuses on RNA-binding proteins and their role in regulating local protein synthesis in neurons.

\section{Transport and translation are linked}

Logically, if protein synthesis were to occur in distinct cellular compartments, mRNAs must be identified shortly after transcription and held in a translationally dormant state during transport to the appropriate compartment. The selection step would be expected to occur at an early time after transcription, so that these messages would be sequestered from the vast protein synthetic machinery located within the cell body. Such a mechanism was recently attributed to the mRNA-binding protein zipcode binding protein 1 (ZBP1) (Huttelmaier et al., 2005). ZBP1 binds to a 54 nucleotide "zipcode" in the 3 '-UTR of $\beta$-actin

Received April 27, 2006; revised May 24, 2006; accepted May 24, 2006.

This work was supported by National Institutes of Health Grant MH66274 and The Ellison Medical Foundation. Correspondence should be addressed to David G. Wells, Department of Molecular, Cellular and Developmental Biology, Yale University, 219 Prospect Street, KBT 226, Box 208103, New Haven, CT 06520-8103. E-mail: david.wells@yale.edu.

DOI:10.1523/JNEUROSCI.1795-06.2006

Copyright $\odot 2006$ Society for Neuroscience $\quad$ 0270-6474/06/267135-04\$15.00/0
mRNA. In neurons, ZBP1 and $\beta$-actin mRNA are partially colocalized in both dendrites and axons (Zhang et al., 2001; Tiruchinapalli et al., 2003). Initially described as a protein involved in mRNA transport, it is now apparent that ZBP1 plays a role in both transport and translational repression. In the NG108-15 neuroblastoma cell line, ZBP1 binds to $\beta$-actin mRNA in the nucleus, translocates into the cytoplasm and acts to repress translation, possibly by preventing the interaction of the $40 \mathrm{~S}$ and $60 \mathrm{~S}$ ribosomal subunits (Huttelmaier et al., 2005).

$\mathrm{ZBP}$ is a member of the heterogeneous nuclear ribonucleoprotein (hnRNP) family of proteins that also includes hnRNP A2 and Fragile X mental retardation protein (FMRP). Staufen 1 and 2 represent the other conserved family of RNA-binding proteins with demonstrable roles in mRNA transport in neurons. Like ZBP1, hnRNP A2, FMRP, and Saufen2 have been shown to shuttle between nucleus and cytoplasm in neurons and to be transported into dendrites (Eberhart et al., 1996; Shan et al., 2003; Kiebler et al., 2005). Although a role for ZBP1 in both mRNA transport and translation has been established, thus far, only a role in transport is ascribed to hnRNP A2 and Staufen2. Once in the cytoplasm, these mRNA-binding proteins and their target mRNAs are packaged into granules for transport out of the cell body (Hirokawa, 2006).

Activity-dependent translation of localized mRNAs likely occurs via a combination of mechanisms, including activation of the general protein synthetic machinery in dendrites and release from repression of specific mRNAs. The latter allows distinct mRNAs to be translated in response to specific stimuli. mRNA translation is a complicated process generally divided into three steps: initiation, elongation, and termination. Translation is primarily regulated during steps one and two by complexes of proteins that interact with the mRNA. Although a detailed description of this process is beyond the scope of this review, there is evidence that suggests local translation in neurons is regulated at the initiation step. Therefore, a brief review of eukaryotic translation initiation is in order.

\section{Regulation of translation initiation}

In eukaryotic cells, synthesis of most proteins is driven by capdependent mRNA translation (Sonenberg and Dever, 2003). Here, translation initiation requires the interaction of the eukaryotic initiation factor (eIF) $4 \mathrm{~F}$ complex with the $5^{\prime}-\mathrm{m}^{7} \mathrm{G}$-cap. 
eIF4F recruits the $43 \mathrm{~S}$ preinitiation complex (including the $40 \mathrm{~S}$ ribosomal subunit) to the $5^{\prime}$ end of the mRNA, which then scans the $5^{\prime}$-UTR for the AUG start codon. At the start codon, part of the initiation complex is dissolved and the $60 \mathrm{~S}$ ribosomal subunit joins the $40 \mathrm{~S}$ subunit to form a translationally competent $80 \mathrm{~S}$ ribosome (Raught et al., 2000). The formation of the initial eIF4F complex is anchored by the cap-binding protein eIF4E and its interaction with eIF4G. Inhibition of $4 \mathrm{E}$ binding to $4 \mathrm{G}$, resulting in a block of translation, is accomplished by eIF4E-binding proteins (4E-BPs) (Sonenberg and Dever, 2003). Phosphorylation of $4 \mathrm{E}-\mathrm{BP}$ inhibits its binding to eIF4E and, thus, would promote initiation complex formation and translation. In addition, eIF4E phosphorylation is also accompanied by an increase in translation rate (Scheper and Proud, 2002). In the hippocampus, both 4E-BP and eIF4E phosphorylation are enhanced by extracellular signal-regulated kinase (ERK) activation (Kelleher et al., 2004; Banko et al., 2005). Thus, synaptic activity that activates the ERK/ MAPK pathway would increase eIF4F complex formation and thereby stimulate translation initiation (Kelleher et al., 2004; Banko et al., 2005). The identity of the specific mRNAs that are translated, however, may depend on other mRNA binding proteins that regulate the availability of the mRNA to participate in cap-dependent translation.

There are at least two mechanisms by which translation of specific mRNAs can be regulated in neurons. The first is through the stabilization of the message. The best described example of this type of translational regulation in neurons is mediated by the ELAV-like protein $\mathrm{HuD}$ (Perrone-Bizzozero and Bolognani, 2002). HuD binds to a 26-nucleotide AU-rich element in the $3^{\prime}$-UTR of the mRNA-encoding growth-associated protein (GAP-43) and selectively stabilizes the mRNA (Kohn et al., 1996; Chung et al., 1997). Initially found to play a role in neurite outgrowth (Anderson et al., 2001), recent studies have described a role for HuD-induced stability of GAP-43 in spatial memory formation in the hippocampus (Pascale et al., 2004). The second mechanism of regulating translation of specific mRNAs involves the derepression of mRNAs that are maintained in a translationally dormant state by the association of mRNA-binding proteins. Perhaps the best-characterized member of this type to be described in neurons is the cytoplasmic polyadenylation element binding protein (Wu et al., 1998).

\section{Control by repression}

CPEB1 was first identified in Xenopus oocytes where it plays a role in oocyte maturation and early embryogenesis (Mendez and Richter, 2001). In neurons, CPEB1 localizes to dendrites and is present at the postsynaptic density (Wu et al., 1998). CPEB1 binds to a specific cis-element in the $3^{\prime}$-UTR of responsive mRNAs and, through a specific 4E-BP called maskin, forms a complex with the $5^{\prime}$-cap that prevents the formation of the initiation complex, thus keeping the mRNA translationally dormant (Fig. 1). CPEB1 harbors a conserved regulatory phosphorylation site $\left(\mathrm{T}^{171}\right.$ and $\mathrm{S}^{177}$ in mice) that can be phosphorylated by either an Aurora A kinase or $\alpha$-calcium/calmodulin-dependent protein kinase II ( $\alpha$-CaMKII) in hippocampal neurons (Huang et al., 2002; Atkins et al., 2004). CPEB1 phosphorylation leads to the elongation of the poly(A)-tail by an atypical poly(A) polymerase, Gld-2 (Barnard et al., 2004), a process thought to recruit eIF4G to the 5 '-cap, dislodging maskin from eIF4E (Cao and Richter, 2002). Presently, two mRNA targets have been identified for CPEB1 in dendrites of mammalian neurons, those encoding $\alpha$-CaMKII and tissue plasminogen activator (Wu et al., 1998; Shin et al., 2004), but more targets are likely to exist (Du and Richter, 2005).

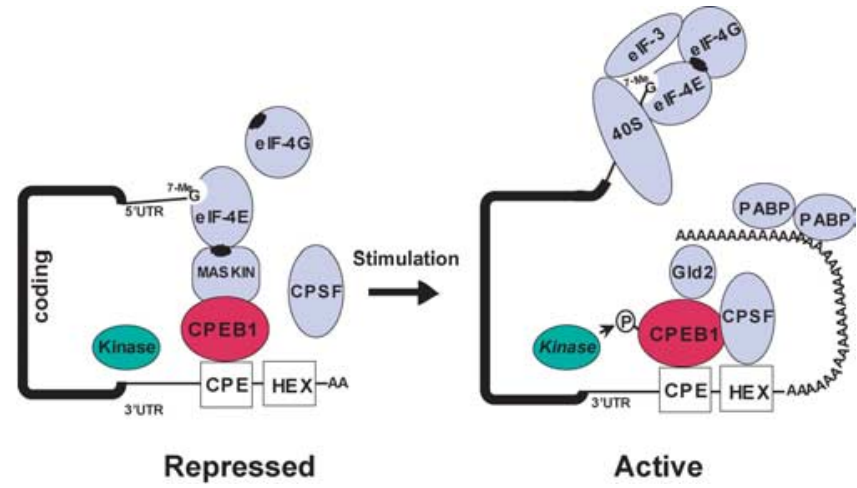

Figure 1. mRNA translation repression and activation mediated by CPEB1. This schematic represents the steps thought to occur during the regulation of mRNA translation of CPEB1bound mRNA. Initially, the $m R N A$ is held in a translationally dormant state by CPEB1 binding to the CPE sequence in the $3^{\prime}$ UTR. Translational repression is accomplished by the interaction of maskin with elF4E. As with most 4E-BPs, maskin binds elF4E at the same site that elF4G binds, thus preventing the formation of the initiation complex. Presumably, mRNA translated in the dendrite are transported in this repressed state. After synaptic activation, CPEB1 phosphorylation (see text) results in the recruitment of cleavage and polyadenylation specificity factor (CPSF) to the hexanucleotide (HEX) sequence and the polyadenylation of the message by GId2. This polyadenylation helps to override the maskin inhibition and elF4G can now bind to elF4E and establish the initiation of translation.

Three other CPEB family members have been identified in mammals (CPEB2-4) based on sequence homology in the RNAbinding domain of these proteins (Theis et al., 2003). CPEB2-4 are expressed in brain, but do not contain the conserved phosphorylation site located in CPEB1. Expression of CPEB3 is induced in the hippocampus after kainate-induced seizures and apCPEB, the CPEB3 homolog in Aplysia, may act as a synapsespecific tag capable of localizing new protein synthesis to previously activated synapses (Si et al., 2003). However, a role for CPEB2-4 in mRNA-binding or in translational regulation has yet to be described.

Using a combination of forward- and reverse-genetic screens in Drosophila to identify genes involved in learning and memory, Dubnau et al. (2003) identified several proteins involved in mRNA translation. Both screens revealed a role for pumilio, a previously identified protein that repressed the expression of Hunchback mRNA in posterior structures during Drosophila embryogenesis (Zamore et al., 1997). Pumilio binds to a specific motif in the $3^{\prime}$-UTR termed the nanos response element and is thought to anchor a complex that includes nanos and brat (Dean et al., 2002). In addition to being implicated in learning and memory (Dubnau et al., 2003), pumilio (and nanos) also play a role in shaping dendritic morphology of specific neurons in the Drosophila (Ye et al., 2004). Unfortunately, the mRNA targets that pumilio regulates in the mammalian brain remain to be elucidated.

FMRP is also thought to regulate mRNA translation in dendrites, at least in part, by repressing translation initiation. Although the specific mechanism(s) of FMRP action are still largely a mystery, when bound to specific mRNAs it can inhibit their synthesis (Laggerbauer et al., 2001; Li et al., 2001). Fragile X mental retardation is a result of the complete loss of FMRP, or mutations that affect the RNA-binding domain (Bagni and Greenough, 2005). Mice and humans lacking FMRP exhibit a change in synaptic morphology and number (Irwin et al., 2001; Nimchinsky et al., 2001) that may lead to behavioral abnormalities (Restivo et al., 2005). FMRP has several different mRNA binding domains including K homology domains, and clusters of arginine and glycine residues (RGG box), which may explain why 
there have been at least four different mechanisms described for how FMRP binds to target mRNA (Bagni and Greenough, 2005). Interestingly, the best characterized mRNA target is fmr 1 , which encodes the FMRP protein itself. FMRP and fmr1 mRNA colocalize to the same transport granules in hippocampal neurons in culture, and their localization into dendrites is enhanced after synaptic activity (Antar et al., 2004). It is widely accepted that activation of the metabotropic glutamate receptor induces an increase in the synthesis of FMRP; however, the consequences of enhanced FMRP levels are, as yet, unclear, because FMRP inhibits translation of some proteins and enhances translation of others [see Mini-Reviews in this series by Grossman et al. (2006) and Pfeiffer et al. (2006)].

Many of the molecular players involved in local protein synthesis are now being elucidated. What is ahead of us is an understanding of how these mRNA-binding proteins interact, cooperate and ultimately regulate individual mRNA species after synaptic activation. Adding to the excitement and confusion is how noncoding RNA and microRNAs (miRNA) work with mRNA binding proteins to regulate translation. In all cases reported to date, miRNAs turn off translation of bound mRNA, possibly through the recruitment of mRNAs into processing or P bodies (He and Hannon, 2004). There are an estimated 125 different miRNAs expressed in the brain (Kosik and Krichevsky, 2005), all likely to further the reign of repression over specific mRNA.

\section{References}

Anderson KD, Sengupta J, Morin M, Neve RL, Valenzuela CF, Perrone-Bizzozero NI (2001) Overexpression of $\mathrm{HuD}$ accelerates neurite outgrowth and increases GAP-43 mRNA expression in cortical neurons and retinoic acidinduced embryonic stem cells in vitro. Exp Neurol 168:250-258.

Antar LN, Afroz R, Dictenberg JB, Carroll RC, Bassell GJ (2004) Metabotropic glutamate receptor activation regulates fragile $\mathrm{X}$ mental retardation protein and Fmrl mRNA localization differentially in dendrites and at synapses. J Neurosci 24:2648-2655.

Atkins CM, Nozaki N, Shigeri Y, Soderling TR (2004) Cytoplasmic polyadenylation element binding protein-dependent protein synthesis is regulated by calcium/calmodulin-dependent protein kinase II. J Neurosci 24:5193-5201.

Bagni C, Greenough WT (2005) From mRNP trafficking to spine dysmorphogenesis: the roots of fragile X syndrome. Nat Rev Neurosci 6:376-387.

Banko JL, Poulin F, Hou L, DeMaria CT, Sonenberg N, Klann E (2005) The translation repressor 4E-BP2 is critical for eIF4F complex formation, synaptic plasticity, and memory in the hippocampus. J Neurosci 25:9581-9590.

Barnard DC, Ryan K, Manley JL, Richter JD (2004) Symplekin and xGLD-2 are required for $\mathrm{CPEB}$-mediated cytoplasmic polyadenylation. Cell 119:641-651.

Cao Q, Richter JD (2002) Dissolution of the maskin-eIF4E complex by cytoplasmic polyadenylation and poly(A)-binding protein controls cyclin B1 mRNA translation and oocyte maturation. EMBO J 21:3852-3862.

Chung S, Eckrich M, Perrone-Bizzozero N, Kohn DT, Furneaux H (1997) The Elav-like proteins bind to a conserved regulatory element in the 3'-untranslated region of GAP-43 mRNA. J Biol Chem 272:6593-6598.

Dean KA, Aggarwal AK, Wharton RP (2002) Translational repressors in Drosophila. Trends Genet 18:572-577.

Du L, Richter JD (2005) Activity-dependent polyadenylation in neurons. RNA 11:1340-1347.

Dubnau J, Chiang AS, Grady L, Barditch J, Gossweiler S, McNeil J, Smith P, BuldocF, Scott R, Certa U, Broger C, Tully T (2003) The staufen/pumilio pathway is involved in Drosophila long-term memory. Curr Biol 13:286-296.

Eberhart DE, Malter HE, Feng Y, Warren ST (1996) The fragile X mental retardation protein is a ribonucleoprotein containing both nuclear localization and nuclear export signals. Hum Mol Genet 5:1083-1091.

Grossman AW, Aldridge GM, Weiler IJ, Greenough WT (2006) Local protein synthesis and spine morphogenesis: fragile $\mathrm{X}$ syndrome and beyond. J Neurosci 26:7151-7155.
He L, Hannon GJ (2004) MicroRNAs: small RNAs with a big role in gene regulation. Nat Rev Genet 5:522-531.

Hirokawa N (2006) mRNA transport in dendrites: RNA granules, motors, and tracks. J Neurosci 26:7139-7142.

Huang Y-S, Jung M-Y, Sarkissian M, Richter JD (2002) N-methyl-Daspartate receptor signaling results in Aurora kinase-catalyzed CPEB phosphorylation and alpha CaMKII mRNA polyadenylation at synapses. EMBO J 21:2139-2148.

Huttelmaier S, Zenklusen D, Lederer M, Dictenberg J, Lorenz M, Meng X, Bassell GJ, Condeelis J, Singer RH (2005) Spatial regulation of betaactin translation by Src-dependent phosphorylation of ZBP1. Nature 438:512-515.

Irwin SA, Patel B, Idupulapati M, Harris JB, Crisostomo RA, Larsen BP, Kooy F, Willems PJ, Cras P, Kozlowski PB, Swain RA, Weiler IJ, Greenough WT (2001) Abnormal dendritic spine characteristics in the temporal and visual cortices of patients with fragile-X syndrome: a quantitative examination. Am J Med Genet 98:161-167.

Kelleher III RJ, Govindarajan A, Jung HY, Kang H, Tonegawa S (2004) Translational control by MAPK signaling in long-term synaptic plasticity and memory. Cell 116:467-479.

Kiebler MA, Jansen RP, Dahm R, Macchi P (2005) A putative nuclear function for mammalian Staufen. Trends Biochem Sci 30:228-231.

Kohn DT, Tsai KC, Cansino VV, Neve RL, Perrone-Bizzozero NI (1996) Role of highly conserved pyrimidine-rich sequences in the 3' untranslated region of the GAP-43 mRNA in mRNA stability and RNA-protein interactions. Brain Res Mol Brain Res 36:240-250.

Kosik KS, Krichevsky AM (2005) The elegance of the microRNAs: a neuronal perspective. Neuron 47:779-782.

Laggerbauer B, Ostareck D, Keidel EM, Ostareck-Lederer A, Fischer U (2001) Evidence that fragile X mental retardation protein is a negative regulator of translation. Hum Mol Genet 10:329-338.

Li Z, Zhang Y, Ku L, Wilkinson KD, Warren ST, Feng Y (2001) The fragile X mental retardation protein inhibits translation via interacting with mRNA. Nucleic Acids Res 29:2276-2283.

Mendez R, Richter JD (2001) Translational control by CPEB: a means to the end. Nat Rev Mol Cell Biol 2:521-529.

Nimchinsky EA, Oberlander AM, Svoboda K (2001) Abnormal development of dendritic spines in FMR1 knock-out mice. J Neurosci 21:5139-5146.

Pascale A, Gusev PA, Amadio M, Dottorini T, Govoni S, Alkon DL, Quattrone A (2004) Increase of the RNA-binding protein $\mathrm{HuD}$ and posttranscriptional up-regulation of the GAP-43 gene during spatial memory. Proc Natl Acad Sci USA 101:1217-1222.

Perrone-Bizzozero N, Bolognani F (2002) Role of $\mathrm{HuD}$ and other RNAbinding proteins in neural development and plasticity. J Neurosci Res 68:121-126.

Pfeiffer BE, Huber KM (2006) Current advances in local protein synthesis and synaptic plasticity. J Neurosci 26:7147-7150.

Raught B, Gingras AC, Sonenberg N (2000) Regulation of ribosomal recruitment in eukaryotes. In: Translational control of gene expression. (Soneneberg N, Hershey JWB, Mathews MB, eds), pp 245-293. Cold Spring Harbor, NY: Cold Spring Harbor Laboratory.

Restivo L, Ferrari F, Passino E, Sgobio C, Bock J, Oostra BA, Bagni C, Ammassari-Teule M (2005) Enriched environment promotes behavioral and morphological recovery in a mouse model for the fragile $\mathrm{X}$ syndrome. Proc Natl Acad Sci USA 102:11557-11562.

Scheper GC, Proud CG (2002) Does phosphorylation of the cap-binding protein eIF4E play a role in translation initiation? Eur J Biochem 269:5350-5359.

Shan J, Munro TP, Barbarese E, Carson JH, Smith R (2003) A molecular mechanism for mRNA trafficking in neuronal dendrites. J Neurosci 23:8859-8866.

Shin CY, Kundel M, Wells DG (2004) Rapid, activity-induced increase in tissue plasminogen activator is mediated by metabotropic glutamate receptor-dependent mRNA translation. J Neurosci 24:9425-9433.

Si K, Giustetto M, Etkin A, Hsu R, Janisiewicz AM, Miniaci MC, Kim J-H, Zhu $\mathrm{H}$, Kandel ER (2003) A neuronal isoform of CPEB regulates local protein synthesis and stabilizes synapse-specific long-term facilitation in Aplysia. Cell 115:893-904.

Sonenberg N, Dever TE (2003) Eukaryotic translation initiation factors and regulators. Curr Opin Struct Biol 13:56-63. 
Steward O, Levy WB (1982) Preferential localization of polyribosomes under the base of dendritic spines in granule cells of the dentate gyrus. J Neurosci 2:284-291.

Theis M, Si K, Kandel ER (2003) Two previously undescribed members of the mouse CPEB family of genes and their inducible expression in the principal cell layers of the hippocampus. Proc Natl Acad Sci USA 100:9602-9607.

Tiruchinapalli DM, Oleynikov Y, Kelic S, Shenoy SM, Hartley A, Stanton PK, Singer RH, Bassell GJ (2003) Activity-dependent trafficking and dynamic localization of zipcode binding protein 1 and $\beta$-actin mRNA in dendrites and spines of hippocampal neurons. J Neurosci 23:3251-3261.

Wu L, Wells D, Tay J, Mendis D, Abbott MA, Barnitt A, Quinlan E, Heynen A,
Fallon JR, Richter JD (1998) CPEB-mediated cytoplasmic polyadenylation and the regulation of experience-dependent translation of alphaCaMKII mRNA at synapses. Neuron 21:1129-1139.

Ye B, Petritsch C, Clark IE, Gavis ER, Jan LY, Jan YN (2004) Nanos and Pumilio are essential for dendrite morphogenesis in Drosophila peripheral neurons. Curr Biol 14:314-321.

Zamore PD, Williamson JR, Lehmann R (1997) The Pumilio protein binds RNA through a conserved domain that defines a new class of RNAbinding proteins. RNA 3:1421-1433.

Zhang HL, Eom T, Oleynikov Y, Shenoy SM, Liebelt DA, Dictenberg JB, Singer RH, Bassell GJ (2001) Neurotrophin-induced transport of a betaactin mRNP complex increases beta-actin levels and stimulates growth cone motility. Neuron 31:261-275. 